\title{
ON THE POSSIBLE DETECTION OF SOLID O2 IN INTERSTELLAR GRAINS
}

\author{
P. EHRENFREUND ${ }^{1,2}$, R. BREUKERS ${ }^{1}$, L. d'HENDECOURT ${ }^{2}$, \\ J.M. GREENBERG ${ }^{1}$ \\ ${ }^{1}$ Huygens Laboratory Astrophysics, Leiden, The Netherlands \\ 2 Groupe de Physique des Solides, Univ. Paris 7, Paris,France
}

\begin{abstract}
In various models of the chemistry of interstellar grains, solid $\mathrm{O}_{2}$ is formed by accretion as well as by surface reactions. In dense molecular cloud models, at a later stage of evolution of an interstellar grain, solid $\mathrm{O}_{2}$ becomes a major grain mantle constituent at the expense of water ice abundance. If molecular oxygen is embedded in a "dirty" ice" matrix, the forbidden fundamental vibration of $\mathrm{O}_{2}$ at $1550 \mathrm{~cm}^{-1}$ may become observable.
\end{abstract}

\section{Introduction}

Oxygen, the cosmic most abundant element after $\mathrm{H}$ and He plays an important role in interstellar chemistry. $\mathrm{O}_{2}$, a diatomic homonuclear molecule shows no transitions in the infrared (IR). Therefore no direct estimates of the abundance can be obtained. We have studied the fundamental band of solid molecular oxygen at $1551 \mathrm{~cm}^{-1}$ in various matrices and discuss the detectability of solid $\mathrm{O}_{2}$ in interstellar grains and its photolysis product, $\mathrm{O}_{3}$.

\section{Results and Discussion}

We could detect the weak vibrational transition of molecular oxygen at $1559 \mathrm{~cm}^{-1}$ in a $\mathrm{CO}_{2}$ matrix at $10 \mathrm{~K}$ and confirm the isotopic shift, using isotopically labelled ${ }^{18} \mathrm{O}_{2}\left(1469 \mathrm{~cm}^{-1}\right)$. Using the well defined integrated absorbance $A_{m}$ of the bending mode of $\mathrm{CO}_{2}$ at $15.2 \mu \mathrm{m}$ (Sandford et al., 1988) we could estimate this value with some accuracy for molecular oxygen: $A_{m}\left(\mathrm{~cm} \cdot \mathrm{mol}^{-1}\right)=3 \times 10^{-18}$. Fig. 1 shows the IR spectum between $4000-500 \mathrm{~cm}^{-1}$ of a gas mixture containing $\mathrm{H}_{2} \mathrm{O}: \mathrm{CO}: \mathrm{O}_{2}: \mathrm{CO}_{2}(2: 2: 1: 0.5)$. The cross section $\mathrm{Am}_{\mathrm{m}}\left(\mathrm{cm} \cdot \mathrm{mol}^{-1}\right)$ is a factor 30 weaker in this complex mixture than in pure and highly diluted $\mathrm{CO}_{2}$. The interaction of polar and polarizable molecules with molecular oxygen in a matrix may be responsible for the enhancement of the weak vibrational transition of $\mathrm{O}_{2}$, a process which can also occur in interstellar grain mantles. Another way to estimate the abundance of $\mathrm{O}_{2}$ on interstellar grains is from a study of its photolysis product $\mathrm{O}_{3}$. Ozone is easily produced by the photodissociation of $\mathrm{O}_{2}$ in the ISM and the $v_{3}$ strongest vibrational transition becomes clearly visible at $1042 \mathrm{~cm}^{-1}(9.6 \mu \mathrm{m})$. Though this band can be obscured by the strong absorption band of silicates at $10 \mu \mathrm{m}$ the sharp feature could be detectable, as well as the overtone of $\mathrm{O}_{3}$ at $2110 \mathrm{~cm}^{-1}$. 


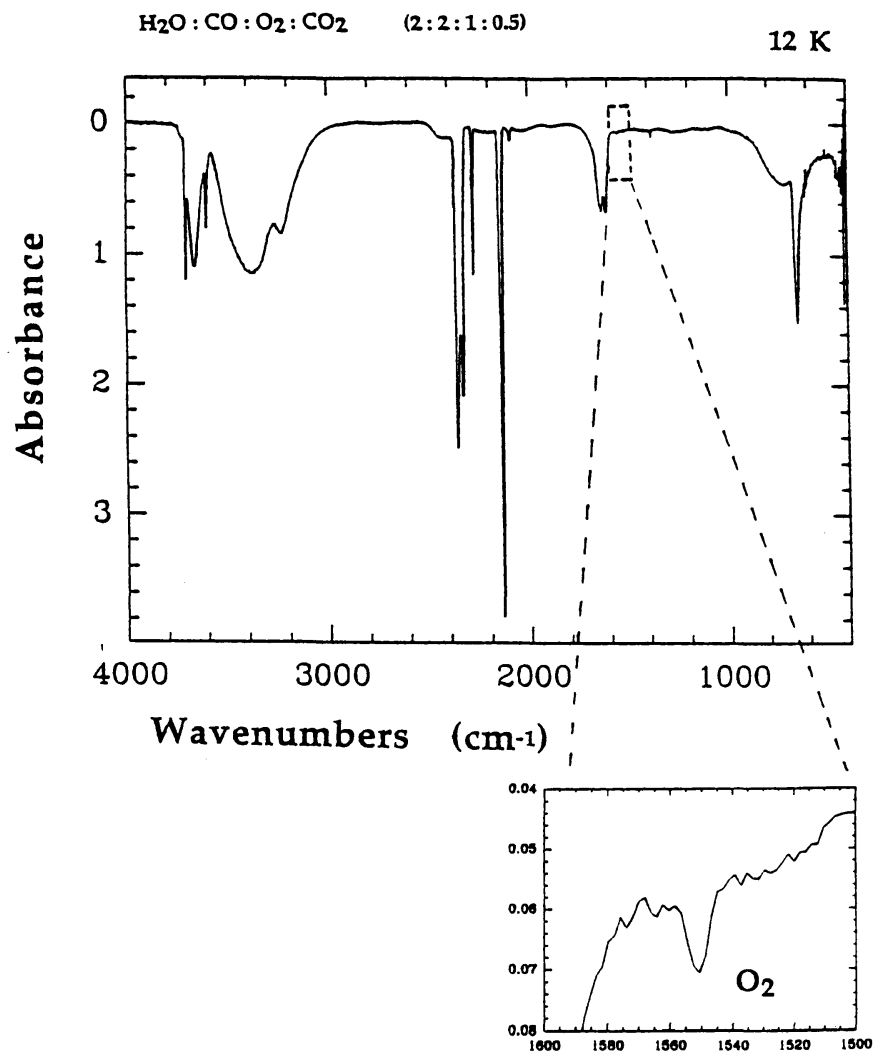

Figure 1. IR spectrum of a "dirty" ice mixture $\mathrm{H}_{2} \mathrm{O}: \mathrm{CO}: \mathrm{O}_{2}: \mathrm{CO}_{2}(2: 2: 1: 0.5)$ at $10 \mathrm{~K}$. The weak fundamental transition of molecular oxygen at $1551 \mathrm{~cm}^{-1}$ is shown in detail.

We want to point out that the results presented here indicate the possible detection of solid $\mathrm{O}_{2}$ in interstellar space in the mid-IR. The calculated integrated absorbance is weak, but can be enhanced by interactions with molecules in the environment, disturbing the symmetry of molecular oxygen. In the theoretical models, $\mathrm{O}_{2}$, becomes a major grain mantle constituent at later times in the evolution of an interstellar grain in dense molecular clouds (Breukers, 1991). The search for the fundamental transition of $\mathrm{O}_{2}$ will probably be successful in astronomical targets like dense molecular clouds, with high extinction and where other grain mantle constituents have already been identified. Furthermore the photolysis product ozone can very likely be observed.

\section{References}

Breukers, R., thesis, Univ. Leiden (1991)

Grimm, R.J.A., d'Hendecourt, L. (1986), A \& A, 167, 161

Herbst, E., Leung, C.M. (1989), Ap.J.Suppl. 69, 271

Sandford, S.A., Allamandola, L., Tielens, A.G.G.M., Valero, G.C. (1988), Ap. J.329, 498 